\title{
Age, Weight and Body Mass Index Effect on Bone Mineral Density in Postmenopausal Women
}

\author{
Farzaneh Montazerifar ${ }^{1,}$; Mansour Karajibani ${ }^{2}$; Sara Alamian ${ }^{3}$; Mahnaz Sandoughi ${ }^{4}$; \\ Zahra Zakeri $^{2,4}$; Ali Reza Dashipour ${ }^{2}$ \\ ${ }^{1}$ Department of Nutrition, School of Medicine, Zahedan University of Medical Sciences, Zahedan, IR Iran \\ ${ }^{2}$ Health Promotion Research Center, Department of Nutrition, School of Medicine, Zahedan University of Medical Sciences, Zahedan, IR Iran \\ ${ }^{3}$ Student Scientific Research Center, School of Medicine, Zahedan University of Medical Sciences, Zahedan, IR Iran \\ ${ }^{4}$ Department of Internal Medicine, Zahedan University of Medical Sciences, Zahedan, IR Iran \\ *Corresponding author: Farzaneh Montazerifar, Department of Nutrition, School of Medicine, Zahedan University of Medical Sciences, Zahedan, IR Iran. Tel: +98-9155416903, Fax: \\ +98-5413425728, E-mail: fmontazerifar@gmail.com
}

Received: August 6, 2013; Revised: November 21, 2013; Accepted: January 24, 2014

Background: Osteoporosis is a multifactorial skeletal disease, whose mechanisms are not fully understood. It is more common in older people, especially in postmenopausal women.

Objectives: Body mass index (BMI) has been suggested as an important measurement to assess bone mineral density (BMD). Therefore, the aim of this study was to assess the effects of age, weight and BMI on BMD in postmenopausal women.

Patients and Methods: In a cross-sectional study based on BMD measurement using dual-energy X-Ray Absorptiometry (DEXA) method, 80 postmenopausal women referred to Rheumatology Clinics in Zahedan were selected; 26 participants had osteoporosis, 28 had osteopenia, and 26 had normal bone density. Weight and height were obtained to calculate BMI.

Results: The mean BMD of women older than 50 years compared to those younger than 50 years was significantly different $(\mathrm{P}<0.05)$. The mean weight and BMI were found to be significantly lower in patients with low BMD as compared to the normal group ( $\mathrm{P}<0.0001)$. There was a negative significant association between age and low BMD only in femur neck region $(r=-0.37, P=0.006)$. In addition, a direct association was observed between weight $(\mathrm{r}=0.41, \mathrm{P}=0.002)$ and $\mathrm{BMI}(\mathrm{r}=0.31, \mathrm{P}=0.02)$ with $\mathrm{BMD}$ at lumbar spine.

Conclusions: The findings indicated that older women with low BMI were at higher risk of low bone mass. Body weight, BMI and aging may be important predictors of BMD, but they are not the only factors affecting bone loss. Therefore, it is recommended to assess other risk factors with a larger number of patients.

Keywords: Bone Density; Body Mass Index; Osteoporosis, Postmenopausal; Achard-Thiers Syndrome

\section{Background}

Osteoporosis is a public health problem worldwide (1, 2 ) and is a common disease in the older population, especially in the postmenopausal women (2-6). The prevalence of osteoporosis in Iranian women has been reported from $6 \%$ to $34.4 \%$ in different cities and provinces (5). This disease is characterized by low bone mass and destruction of bone tissue, leading to increased fracture risk $(1,2,6)$. Several studied have shown that in addition to the risk factors such as aging, lack of physical activity, smoking, premature menopause, family history, poor diet and low intake of calcium and vitamin $\mathrm{D}(3,5,7-12)$, other factors, including body weight (13-15) and BMI (1, $3,5,9,11-13,16)$ are also important in the risk assessment tools, which contribute to osteoporosis and osteoporotic fracture risk. Measurement of body mass index is an inexpensive and valuable technique to guide public health policy, clinical decisions, and evaluation of nutritional status (17-19). Decreased BMD in postmenopausal women with lower BMI is more than those with higher BMI $(13,16)$. Changes of BMD in weight loss may be related to the role of soft tissue in disturbance with bone densitometry by DEXA. However, the relation between body mass index and higher BMD remains ambiguous (13). The importance of both BMI and aging on bone mass density has been shown in previous studies $(3-6,12)$. Calcium and other bone minerals are reduced by aging. As a result, bones become thinner and more fragile, leading to osteoporosis $(1,2,17,20)$. Considering to exponential rise in the number of fractures and risk factors of bone mass loss among older adults, early diagnosis and identification of the factors associated with bone loss and its complications could be effective in the management of disease and therapeutic decisions of those with risk factors of low $\operatorname{BMD}(2,12)$. risk. 


\section{Objectives}

Since among the anthropometric parameters, weight and BMI have been recognized as good predictors for the evaluation of osteoporosis and osteoporotic fracture risk (1), in the present study, we evaluated the effect of age, weight and BMI on BMD in postmenopausal women.

\section{Patients and Methods}

Eighty postmenopausal women aged 35 - 79 years old referred to two Rheumatology Clinics in Zahedan were enrolled. The exclusion criteria were hyperthyroidism, diabetes mellitus, renal or liver disease, rheumatoid arthritis or a history of treatment with Levothyroxine, furosemide, heparin, phenytoin, phenobarbital, vitamin $\mathrm{K}$, ranitidine, calcium carbonate and vitamin D3 and corticosteroids, alcohol consumption and smoking. The participants were referred to the bone densitometry center. Bone Mineral Density (BMD) was measured using Dual Energy X-ray Absorptiometry method (DEXA) (GE-Lunar Radiation Corporation, DPX MD + 73457 models, Madison, WI, USA) at femur neck and the second to fourth lumbar spine. Osteoporosis and osteopenia were assessed based on t-scores from BMD measurements as defined by the World Health Organization (WHO): t-score $<-2.5$ was considered as osteoporosis; -1 $\geq \mathrm{t}$-score $>-2.5$ as osteopenia, and those with t-scores $>-1$ were considered as normal (21).

Participants were divided into three groups based on BMD, 26 with osteoporosis, 28 with osteopenia and 26 with normal bone density (as control group). The height and weight of patients were measured at the time of the DXA scans with a stadiometer and a clinical scale with a precision of $0.5 \mathrm{~cm}$ and $100 \mathrm{~g}$, respectively. Participants were dressed in light clothes without wearing shoes. Body mass index (BMI) was calculated as the weight in kilograms divided by height in meters squared (weight $\left.(\mathrm{kg}) /[\text { height }(\mathrm{m})]^{2}\right)(17,22)$. BMI was categorized based on the guidelines reported by centers for disease control (CDC) (23) as follows; equal or below 18.5 was considered as underweight, 18.5 to 24.9 as normal and $\geq 25 \mathrm{~kg} / \mathrm{m}^{2}$ as overweight and obese. The ethics committee of the Zahedan University of Medical Sciences approved the study, and informed consent was orally obtained from all patients and healthy individuals.

\subsection{Statistical Analysis}

Data was analyzed using statistical package for social sciences (SPSS) software, version 18.0. All data were normally distributed and expressed as mean \pm SD. One-way analysis of variance (ANOVA) and Tukey test were used for comparison between the three groups. Independent sample t-test and Chi-square test were also used. The correlations between the variables were calculated by Pearson correlation test. P value $<0.05$ was considered significant.

\section{Results}

The study population included 80 postmenopausal women; the mean age was $54.8 \pm 8.1$ years. The mean body weight was $71.4 \pm 13.6 \mathrm{~kg}$, and the mean BMI was $29.1 \pm 5.9 \mathrm{~kg} / \mathrm{m}^{2}$. There was a significant difference between the mean age in patients with osteoporosis and control group ( $\mathrm{P}<0.05)$. The mean weight and BMI were significantly lower in patients with osteoporosis and osteopenia compared to the control group ( $\mathrm{P}<$ 0.0001). However, the mean weight and BMI values of the two groups did not differ significantly. The demographic data is shown in Table 1 . Subjects' distribution based on age and BMI, are summarized in Table 2.

Compared with the normal group, $27.3 \%$ and $31.8 \%$ of women younger than 50 years, and $34.5 \%$ and $36.2 \%$ of those aged 50 years or above had osteoporosis and osteopenia, respectively. The frequency of osteoporosis and osteopenia were $47.6 \%$ and $28.6 \%$ in women with normal BMI, and $27.1 \%$ and $37.3 \%$ in those with overweight and obese. None of the studied individuals were underweight. DEXA scan results are shown in Table 3 based on the t-score values at the femoral neck and lumber spinal region regarding age and BMI. The findings revealed that the mean t-score values of women older than 50 years were significantly different at both femoral neck and lumbar spine $(\mathrm{P}<0.05)$ compared to those younger than 50 years. In addition, the mean BMD in overweight women was higher compared to normal weight women (although the values did not differ significantly $(\mathrm{P}>0.05)$. Table 4 describes the correlation coefficients between the variables in the studied populations. There was a negative significant association between age and low BMD only in femur neck region $(\mathrm{r}=-0.37, \mathrm{P}=0.006)$. Moreover, a direct association was found between weight $(\mathrm{r}=0.41, \mathrm{P}=0.002)$ and $\mathrm{BMI}(\mathrm{r}=$ $0.31, \mathrm{P}=0.02$ ) at lumbar spine region, while such a significant correlation was not seen at the femoral neck region.

Table 1. Demographic Characteristics of the Studied Population a

\begin{tabular}{lccc}
\hline Variables & $\begin{array}{c}\text { Osteoporosis } \\
(\mathbf{n = 2 6})\end{array}$ & $\begin{array}{c}\text { Osteopenia } \\
(\mathbf{n = 2 8})\end{array}$ & $\begin{array}{c}\text { Normal } \\
(\mathbf{n = 2 6})\end{array}$ \\
\hline Age, $\mathbf{y}$ & $58 \pm 8.4^{\mathrm{b}}$ & $53.7 \pm 7.2$ & $52.7 \pm 8$ \\
Weight, kg & $63 \pm 10.2^{\mathrm{C}}$ & $69 \pm 10.4^{\mathrm{c}}$ & $82 \pm 12.4$ \\
\hline Height, $\mathbf{~ c m}$ & $154.7 \pm 5.2$ & $157.2 \pm 5.5$ & $157.8 \pm 8.3$ \\
\hline $\begin{array}{l}\text { Body Mass } \\
\text { index, kg/m }\end{array}$ & $26.2 \pm 3.6^{\mathrm{C}}$ & $27.9 \pm 4^{\mathrm{C}}$ & $33.5 \pm 7.1$ \\
\hline
\end{tabular}

a Values are presented in mean \pm SD.

$\mathrm{b} \mathrm{P}<0.05$ vs. normal group.

${ }^{\mathrm{C}} \mathrm{P}<0.0001$ vs. normal group. 
Table 2. Distribution of Patients Based on Age and Body Mass Index $^{a}$

\begin{tabular}{|c|c|c|c|c|}
\hline $\begin{array}{l}\text { Osteoporosis } \\
\text { Variable }\end{array}$ & Osteopenia & Normal & No.(\%) & Pvalue \\
\hline Age, $y$ & & & & 0.35 \\
\hline$<50$ & $6(27.3)$ & $7(31.8)$ & $9(40.9)$ & \\
\hline$\geq 50$ & $20(34.5)$ & $21(36.2)$ & $17(29.3)$ & \\
\hline $\begin{array}{l}\text { Body Mass } \\
\text { Index, } \mathrm{kg} / \mathrm{m}^{2}\end{array}$ & & & & 0.17 \\
\hline Normal & $10(47.6)$ & $6(28.6)$ & $5(23.8 \%)$ & \\
\hline $\begin{array}{l}\text { Overweight } \\
\text { and obese }\end{array}$ & $16(27.1)$ & $22(37.3)$ & $21(35.6)$ & \\
\hline
\end{tabular}

Table 3. Comparison Between Mean t-Score Values in Postmenopausal Women With Bone Mineral Density Regarding Age and Body Mass Index

\begin{tabular}{lcc}
\hline Variables & Femoral Neck & Lumbar Spine \\
\hline Age, $\mathbf{y}$ & & \\
$<50(\mathrm{n}=13)$ & $-1.3 \pm 0.4$ & $-1.9 \pm 0.9$ \\
& $(-3$ to -0.3$)$ & $(-3.4$ to -0.3$)$ \\
\hline $50(\mathrm{n}=41)$ & $-1.9 \pm 1$ & $-2.43 \pm 1.25$ \\
& $(-3.7$ to -0.2$)$ & $(-5.2$ to -0.4$)$ \\
\hline P value & 0.045 & 0.032 \\
\hline Body Mass Index & & \\
\hline Normal weight $(\mathrm{n}=16)$ & $-2 \pm 0.9$ & $-2.68 \pm 1.2$ \\
& $(-3.1$ to -0.7$)$ & $(-4.3$ to -1$)$ \\
\hline $\begin{array}{l}\text { Overweight and obese } \\
\text { ( } \mathrm{n}=38)\end{array}$ & $-1.69 \pm 1$ & $-2.1 \pm 1.18$ \\
\hline P value & $(-3.7$ to -0.2$)$ & $(-5.2$ to -0.3$)$ \\
\hline & Not significant & Not significant \\
\hline
\end{tabular}

Table 4. Correlation Between Bone Mineral Density and the Variables in the Studied Population

\begin{tabular}{lcc}
\hline Variables & Femur Neck & Lumbar Spine \\
\hline Age, $\mathbf{y}$ & $\mathrm{r}=-0.37$ & $\mathrm{r}=0.25$ \\
Weight, kg & $\mathrm{P}=0.006$ & $\mathrm{P}^{\mathrm{a}}=0.070$ \\
& $\mathrm{r}=0.152$ & $\mathrm{r}=0.41$ \\
$\mathbf{B M I}, \mathbf{k g} / \mathbf{m}^{\mathbf{2}}$ & $\mathrm{P}^{\mathrm{a}}=0.273$ & $\mathrm{P}=0.002$ \\
& $\mathrm{r}=0.209$ & $\mathrm{r}=0.315$ \\
\hline
\end{tabular}

a Not significant.

\section{Discussion}

We investigated three factors including age, weight and body mass index, which may affect bone loss in postmenopausal women. Although, the effects of these factors on bone are as yet uncertain, some studies have shown that aging and menopause are the two major factors likely to be associated with increasing risk of bone tissue destruction $(1-3,5,8,11,12,20)$. At the present study, bone mineral density levels also decreased with aging. An inverse correlation between age and BMD at the femoral neck in the present study, suggests that advancing age is associated with lower BMD. This fact is consistent with the results of Chanprasertyothin et al. (24) and Douchi et al. (25) studies. A positive significant correlation between age and BMD at both lumbar spine and femoral neck (16, 26) and a direct correlation between age and lumbar spine BMD were also observed in recent studies $(27,28)$. Despite the fact, Lofman et al. (29), Saravi et al. (4), and Mazess et al. (26) reported no effect of age on BMD. Low body mass index has been described as a predictor for the evaluation of both osteoporosis and increased fracture risk in the Black et al. (16) and van der Voort et al. studies (9). In our study, mean weight and BMI were also found to be significantly lower in patients with osteoporosis and osteopenia as compared to the normal group. However, the mean weight and BMI values of the two groups of patients did not differ significantly. Other studies have also shown an association between body weight $(14,15)$ and $\operatorname{BMI}(1,11,22,30-33)$ with BMD. But, Saravi et al. (4) reported no significant effect of BMI on BMD. Furthermore, the results showed that $76.2 \%$ of patients with osteoporosis and osteopenia had normal BMI, and 64.4\% were overweight which was approximately similar to the study conducted by Fawzy et al. (1). However, it has been suggested that postmenopausal women with lower BMI have more bone loss than those with higher BMI. Although in this study obese women had higher BMD than those with normal weight, it was not significantly different $(P>0.05)$. Albala et al. (34) also reported similar findings that obese women after menopause have higher bone mass than normal weight age-matched women, especially at lumbar spine and femoral neck.

Moreover, in some studies as shown in the present study, a positive significant correlation was found between body weight and BMI with BMD at the lumbar spine, but not at the femoral neck, $(3,4)$. A positive correlation between BMI and BMD at the femoral neck of postmenopausal women was seen by Bayat et al. (12) and Steinschneider et al. (13). Increased BMD in obese women may be due to the role of soft tissue in interfering with BMD determination by DEXA, $(1,13)$ which decreases the accuracy of BMD measurements (35). As shown in our study, low BMD has been reported with both aging and low body weight in some studies $(3-5,12)$. Other similar studies found a significant correlation between osteopenia and osteoporosis with aging and lower BMI $(4,12)$. Despite numerous reports on the association between aging and BMI with bone mass, the exact mechanisms are not fully identified yet; however, some studies suggested that humoral factors related to body fat mass, in particu- 
lar low ovarian estrogen production in postmenopausal women may affect lumbar spine BMD and bone loss (25). The findings indicated that older women with low BMI were at higher risk of low bone mass. Body weight, BMI and aging might be important predictors of BMD, but they are not the only factors affecting bone loss. Thus, it is recommended to assess other risk factors with a larger number of patients.

\section{Acknowledgements}

The authors would like to thank all patients who participated in the study. In addition, we gratefully appreciate Mrs. Khamar for performing bone densitometry and Mr. Vazifedan for data collection.

\section{Authors' Contribution}

Drafting and preparing the manuscript: Farzaneh Montazerifar and Mansour Karajibani; performing statistical analysis: Farzaneh Montazerifar; data collection: Sara Alamian; conducting the study: Farzaneh Montazerifar, Sara Alamian, Mahnaz Sandughie and Zahra Zakeri; cooperation in statistical analysis: Ali Reza Dashipour.

\section{Financial Disclosure}

The authors had no conflicts of interests.

\section{Funding/Support}

The present paper was part of a research project approved by the Health Promotion Research Center of Zahedan University of Medical Sciences (grant No. 245730.11.2013).

\section{References}

1. Fawzy T, Muttappallymyalil J, Sreedharan J, Ahmed A, Alsham si SO, Al Ali MS, et al. Association between Body Mass Index and Bone Mineral Density in Patients Referred for Dual-Energy X-Ray Absorptiometry Scan in Ajman, UAE. J Osteoporos. 2011;2011:876309.

2. Srivastava M, Deal C. Osteoporosis in elderly: prevention and treatment. Clin Geriatr Med. 2002;18(3):529-55.

3. Reginster JY, Burlet N. Osteoporosis: a still increasing prevalence. Bone. 2006;38(2 Suppl 1):S4-9.

4. Saravi FD, Sayegh F. Bone mineral density and body composition of adult premenopausal women with three levels of physical activity. J Osteoporos. 2013;2013:953271.

5. Aghaei M, Afshan B, Reza H, Qorbani M, Dashti HS, Safari R. Bone mineral density in Iranian patients: Effects of age, sex, and body mass index. Open J Prev Med . 2013;3(1):128-31.

6. Larijani AMB, Soltani A, Pazhouhi M, Bastanhagh M, Mirfeizi SZ, Dashti R, et al. [Bone mineral density variations in 20-69 yr population of Tehran/Iran]. Iran South Med J. 2002;1(5):41-9.

7. Jarupanich T. Prevalence and risk factors associated with osteoporosis in women attending menopause clinic at Hat Yai Regional Hospital. J Med Assoc Thai. 2007;90(5):865-9.

8. Chris T, Derk MD. Osteoporosis in premenopausal. Postgrad Med. 2006;119(1):1635-6.

9. van der Voort DJ, Geusens PP, Dinant GJ. Risk factors for osteoporosis related to their outcome: fractures. Osteoporos Int.
2001;12(8):630-8.

10. Brown JP, Josse RG. Clinical practice guidelines for the diagnosis and management of osteoporosis in Canada. CMAJ 2002;167:1-34

11. Baheiraei A, Pocock NA, Eisman JA, Nguyen ND, Nguyen TV. Bone mineral density, body mass index and cigarette smoking among Iranian women: implications for prevention. BMC Musculoskelet Disord. 2005;6:34.

12. Bayat N, Hajiamini Z, Paidar M, Ebadi A, Parandeh A. [Risk factors of low bone mineral density in premenopausal women]. MilMed J. 2010;12(1):1-6.

13. Steinschneider M, Hagag P, Rapoport MJ, Weiss M. Discordant effect of body mass index on bone mineral density and speed of sound. BMC Musculoskelet Disord. 2003;4:15.

14. Rico H, Revilla M, Villa LF, Alvarez del Buergo M, Ruiz-Contreras D. Determinants of total-body and regional bone mineral content and density in postpubertal normal women. Metabolism. 1994;43(2):263-6.

15. Henderson NK, Price RI, Cole JH, Gutteridge DH, Bhagat CI Bone density in young women is associated with body weight and muscle strength but not dietary intakes. J Bone Miner Res. 1995;10(3):384-93.

16. Black DM, Steinbuch M, Palermo L, Dargent-Molina P, Lindsay R, Hoseyni MS, et al. An assessment tool for predicting fracture risk in postmenopausal women. Osteoporos Int. 2001;12(7):51928.

17. Mahan LK, Escott-Stump S, Raymond JL, Krause MV. Krause's Food \& the Nutrition Care Process. 13 ed. US: Elsevier/Saunders 2012.

18. Cook Z, Kirk S, Lawrenson S, Sandford S. Use of BMI in the assessment of undernutrition in older subjects: reflecting on practice. Proc Nutr Soc. 2005;64(3):313-7.

19. WHO Expert Committee. Physical status: the use and interpre tation of anthropometry. Geneva: World Health Organization 1995. Available from: http://www.who.int/childgrowth/publications/physical_status/en/.

20. Salamat MR, Abedi I, Salamat AH, Babanoori G. [Evaluating the relationships between body mass index, weight and bone mineral density in men using dual-energy X-ray absorptiometry]. Isfahan Med Sch. 2013;30(222):2545-56.

21. Assessment of fracture risk and its application to screening for postmenopausal osteoporosis. Report of a WHO Study Group. World Health Organ Tech Rep Ser. 1994;843:1-29.

22. Puntus T, Schneider B, Meran J, Peterlik M, Kudlacek S. Influence of age and gender on associations of body mass index with bone mineral density, bone turnover markers and circulating calcium-regulating and bone-active sex hormones. Bone. 2011;49(4):824-9.

23. Centers for Disease Control and Prevention. Healthy Weight it's not a diet, it's a lifestyle! About BMI for adults. 2009. [Updated 13 September 2011]; Available from: http://www.cdc.gov/ healthyweight/assessing/bmi/adult_BMI/index.html.

24. Chanprasertyothin S, Saetung S, Payattikul P, Rajatanavin R, Ongphiphadhanakul B. Relationship of body composition and circulatory adiponectin to bone mineral density in young premenopausal women. J Med Assoc Thai. 2006;89(10):1579-83.

25. Douchi T, Yamamoto S, Oki T, Maruta K, Kuwahata R, Nagata Y. Relationship between body fat distribution and bone mineral density in premenopausal Japanese women. Obstet Gynecol. 2000;95(5):722-5.

26. Mazess RB, Barden HS. Bone density in premenopausal women effects of age, dietary intake, physical activity, smoking, and birth-control pills. Am J Clin Nutr.1991;53(1):132-42.

27. MacInnis RJ, Cassar C, Nowson CA, Paton LM, Flicker L, Hop per JL, et al. Determinants of bone density in 30- to 65-year-old women: a co-twin study. J Bone Miner Res. 2003;18(9):1650-6.

28. Sabatier JP, Guaydier-Souquieres G, Benmalek A, Marcelli C. Evolution of lumbar bone mineral content during adolescence and adulthood: a longitudinal study in 395 healthy females 1024 years of age and 206 premenopausal women. Osteoporos Int 1999;9(6):476-82. 
29. Lofman O, Larsson L, Ross I, Toss G, Berglund K. Bone mineral density in normal Swedish women. Bone. 1997;20(2):167-74.

30. Langsetmo L, Hitchcock CL, Kingwell EJ, Davison KS, Berger C, Forsmo S, et al. Physical activity, body mass index and bone mineral density-associations in a prospective populationbased cohort of women and men: the Canadian Multicentre Osteoporosis Study (CaMos). Bone. 2012;50(1):401-8.

31. Iqbal SI, Morch LS, Rosenzweig M, Dela F. The outcome of bone mineral density measurements on patients referred from general practice. J Clin Densitom. 2005;8(2):178-82.

32. Robbins J, Schott AM, Azari R, Kronmal R. Body mass index is not a good predictor of bone density: results from WHI, CHS, and EPIDOS. J Clin Densitom. 2006;9(3):329-34.

33. Nguyen TV, Center JR, Eisman JA. Osteoporosis in elderly men and women: effects of dietary calcium, physical activity, and body mass index. J Bone Miner Res. 2000;15(2):322-31.

34. Albala C, Yanez M, Devoto E, Sostin C, Zeballos L, Santos JL. Obesity as a protective factor for postmenopausal osteoporosis. Int J Obes Relat Metab Disord.1996;20(11):1027-32.

35. Patel R, Blake GM, Rymer J, Fogelman I. Long-term precision of DXA scanning assessed over seven years in forty postmenopausal women. Osteoporos Int. 2000;11(1):68-75. 